Gut, 1986, 27, 1025-1028

\title{
Depression and functional bowel disorders in gastrointestinal outpatients
}

\author{
J D R ROSE, A H TROUGHTON, J S HARVEY, AND P M SMITH \\ From the University Hospital of Wales, and Llandough Hospital, Cardiff
}

SUMMARY Although depression has been linked with both the irritable bowel syndrome and non-organic abdominal pain, which are common in gastrointestinal outpatients, the prevalence of depression in most surveys of outpatient practice has been low. Use of the Beck Depression Inventory to screen new referrals to a general medical and gastrointestinal clinic and to a minor surgical clinic showed that 50 of 100 medical patients were rated as having some degree of depression, compared with 14 of $75(19 \%)$ of the surgical patients in whom abdominal pain and bowel dysfunction were rare $\left(\chi^{2}=9 \cdot 6, p<0 \cdot 01\right)$. In the medical clinic no organic disorder was detected in $64 \%$ of the depressed patients, the majority of whom presented with abdominal pain or irritable bowel syndrome. Depression was significantly commoner in this group of patients than in those with other conditions, $\left(\chi^{2}=6.63, p=0.01\right)$. That depression is common in gastrointestinal outpatients is not always appreciated and its symptoms should be sought in all patients with bowel dysfunction and chronic abdominal pain.

It has often been noted that patients with the irritable bowel syndrome may suffer from depression, the prevalence varying widely from $9 \%^{1}$ to $45 \%{ }^{2}$ Some authors consider irritable bowel syndrome to be an integral part of depression,,$^{3-5}$ and it may also be found in up to a third of patients with non-organic abdominal pain. ${ }^{6} 7$

Most gastrointestinal outpatients do not have identifiable organic illness and suffer from functional disorders such as irritable bowel syndrome and chronic non-organic abdominal pain ${ }^{-10}$ but in two large published series the proportion of patients diagnosed as being depressed was $2 \cdot 5 \%$ and $0 \% .910$ If there is a connection between depression and these disorders, depression should be commoner in gastrointestinal outpatients. Specially constructed research interviews with patients in a gastrointestinal clinic have revealed a psychiatric diagnosis in almost half the patients, ${ }^{11}$ but without such psychiatric screening, physicians miss the diagnosis of depression in half their affected outpatients. ${ }^{12}$ Several questionnaires of psychiatric symptoms are available, of which the Beck Depression Inventory ${ }^{13}$ has been recommended for screening in general

Address for correspondence: Dr P M Smith, Llandough Hospital, Penarth, S Glamorgan.

Received for publication 17 January 1986. practice $^{14}$ and has been modified to a short selfassessment form, easily completed in a few minutes without supervision. ${ }^{15}$

The aims of this study were to use the inventory to establish the number of patients suffering from depression among new referrals to a general medical and gastrointestinal clinic and to a general surgical clinic, to determine with what symptoms and conditions depressed patients presented, and to see whether the inventory scores affected the readiness of the clinician to prescribe antidepressants.

\section{Methods}

\section{PATIENTS}

Consecutive new referrals to a general surgical and to a general medical and gastrointestinal outpatient clinic, with similar waiting lists and held in the same Health Authority area, were asked to fill in the Beck Depression Inventory on arrival. Alternate completed forms were handed to the clinician; the others were retained unseen as controls.

Depression was diagnosed from the inventory score using the criteria of Beck and Beck. ${ }^{15}$ An independent diagnosis of depression by the clinician was considered to have been made if an antidepressant was prescribed. To avoid artificially increasing the clinical diagnosis, no separate formal assessment 
of depression was requested. Investigation and management of the patients' medical problems were not stipulated and diagnoses were made according to usual clinical practice.

\section{Results}

\section{MEDICAL CLINIC}

One hundred and ten consecutive new referrals were asked to fill in the Beck Depression Inventory. Two patients refused, one non-English speaker was unable to understand the questions and seven forms were incomplete, leaving 100 acceptable inventories $(91 \%)$. There were 41 men and 59 women (one M:1.4F) with a mean age of 46.7 years (range 16-87). Fifty patients scored less than 5 and were rated as normal. Fifty patients scored in the depressive range, however, 21 from 5-7 (mild), 20 from 8-15 (moderate) and nine more than 15 (severe). The highest score was 30 , the maximum possible being 39 . Four patients felt they would be better off dead and two others were suicidal. One patient, who complained of abdominal bloating but denied suicidal intentions, died of an overdose of paracetamol and dextropropoxyphene a few days after being prescribed anti-depressants. No gastrointestinal pathology was found at necropsy examination.

The mean ages of patients without depression (45.7 years) and those with mild, moderate or severe depression (49.4, 44 and 50.8 years respectively) were similar. The male:female ratio, however, was $1: 1$ in those who were not depressed but $1: 2 \cdot 3$ in the depressed patients.

Thirty two of the depressed patients $(64 \%)$ were diagnosed as suffering from functional disorder on the basis of the history and appropriate investigations. The commonest symptoms were altered bowel habit with abdominal pain - irritable bowel syndrome - and chronic abdominal pain without alteration of bowel function. Together, these two complaints were significantly commoner in the depressed group $\left(\chi^{2}=6.63, p=0.01\right)$, while organic disorders were commoner in the non-depressed group $\left(\chi^{2}=4 \cdot 0, p<0 \cdot 05\right.$, Table 1$)$. In several of the patients with depression and organic disease, this was a chronic stable condition, such as mitral valve disease, which was unrelated to the presenting functional symptom.

The proportion of patients diagnosed clinically as being depressed increased with the severity of the depression as rated by the inventory (Table 2). No patient who scored less than 5 was prescribed antidepressants. Although for all grades of depression the proportion of patients prescribed antidepressants was greater if the inventory score was available, no statistical significance was achieved.
Table 1 Clinical diagnoses of 100 consecutive outpatients and their Beck depression inventory rating

\begin{tabular}{|c|c|c|c|c|}
\hline & & \multicolumn{3}{|c|}{$\begin{array}{l}\text { Beck depression inventory rating } \\
<5 \quad 5 \text { or more }\end{array}$} \\
\hline \multirow{4}{*}{\multicolumn{2}{|c|}{$\begin{array}{l}\text { Irritable bowel syndrome } \\
\text { Non-organic abdominal pain } \\
\text { Other functional } \\
\text { gastrointestintal disorders }\end{array}$}} & 6 & \multicolumn{2}{|l|}{13} \\
\hline & & $\mathbf{0}$ & \multirow{2}{*}{5} & \\
\hline & & & & \\
\hline & & $13^{*}$ & $6+$ & \\
\hline \multirow{2}{*}{\multicolumn{2}{|c|}{$\begin{array}{l}\text { Non-gastrointestinal functional } \\
\text { disorders }\end{array}$}} & & \multirow[b]{2}{*}{8} & \\
\hline & & 3 & & \\
\hline \multicolumn{2}{|c|}{ Organic disease } & 28 & 18 & \\
\hline Total & & 50 & 50 & \\
\hline \multicolumn{5}{|c|}{$\begin{array}{l}\text { *Constipation } 3 \text {, aerophagy } 3 \text {, dyspepsia } 3 \text {, vomiting } 2 \\
\text { oesophageal pain } 1 \text {, transient weight loss } 1 . \\
\text { †Vomiting } 3 \text {, aerophagy } 2 \text {, dyspepsia } 1 \text {. }\end{array}$} \\
\hline \multicolumn{5}{|c|}{$\begin{array}{l}\text { Table } 2 \text { Depression rating of } 100 \text { consecutive referrals } \\
\text { using the Beck depression inventory and the proportion } \\
\text { diagnosed clinically }\end{array}$} \\
\hline Depression rating & Nil & Mild & Moderate & Severe \\
\hline Patients (n) & 50 & 21 & 20 & 9 \\
\hline Diagnosed clinically (n) & $\mathbf{0}$ & 6 & 11 & 6 \\
\hline Diagnosed clinically $(\%)$ & 0 & 29 & 55 & 66 \\
\hline
\end{tabular}

Like the result of any other test, the inventory score when abnormal was not always acted upon. Thirteen patients, rated as depressed, did not have antidepressants prescribed. In nine of these the depression was mild; the only patient with severe depression whose inventory score was not acted upon was admitted immediately because of alcoholism.

\section{SURGICAL CLINIC}

Of 77 new referrals to a general, predominantly minor, surgical outpatient clinic, 75 (97\%) completed the Beck Depression Inventory; the others refused. There were 42 men and 33 women (1M:0.8F) with a mean age of 44.9 years (range $19-83)$. Sixty one patients $(81 \%)$ scored less than 5 , nine $(12 \%)$ were rated as mildly, four $(5.4 \%)$ moderately and one $(1.3 \%)$ as severely depressed. In two of the depressed patients no organic lesion was found to explain their symptoms but the other had minor lesions susceptible to surgical correction. Only three patients were referred because of abdominal pain or bowel dysfunction. One of these had non-organic pain and was not depressed. The clinical diagnosis of depression was made in another for whom the inventory score was available. 


\section{Discussion}

This study using a self-assessment questionnaire showed that half the patients attending a general medical and gastrointestinal clinic exhibited some degree of depression, which was severe in approximately $10 \%$. In a similar study using both interview and questionnaire the proportion of patients with a psychiatric diagnosis was of the same order. ${ }^{11} \mathrm{We}$ conclude that the reason why depression has a low prevalence in studies of clinical practice is that it is underdiagnosed. Even in this study undertaken by interested clinicians, only two-thirds of severely depressed patients were diagnosed and treated.

Symptoms of chronic non-organic abdominal pain and irritable bowel syndrome were significantly more common in the depressed group and this supports the findings of Macdonald and Bouchier that a diagnosis of non-organic illness predicted a psychiatric diagnosis on interview by a psychiatrist. ${ }^{11}$ Our data do not support the often proferred explanation that the symptoms of an as yet undiagnosed organic disease are the cause of a secondary depression in these patients. Organic disease was significantly more likely to be associated with a normal inventory score. Depression was also uncommon in the minor surgical clinic, in which gastrointestinal symptoms and functional disorders were rare but organic problems common.

The results of the study confirm a relationship between irritable bowel syndrome and non-organic abdominal pain, and depression. They are also compatible with both the hypothesis that such symptoms are an integral part of depression, ${ }^{45}$ and the suggestion that psychosocial circumstances drive patients to consult doctors about complaints, which are known to be common in the uncomplaining majority. ${ }^{16}{ }^{17}$ In this connection it is of interest that in many of the depressed patients with organic disease it appeared that the onset of depression in an otherwise stable condition had led to the referral. A similar mechanism may well operate in functional disorders. Life circumstances can be important in determining the course of these disorders. ${ }^{18}$

Knowledge of the inventory score appeared to exert an influence on the prescription of antidepressants but not to an extent which satisfied statistical criteria of significance. There was, nevertheless, an educational value as the inventory scores often showed psychopathology in patients in which it was unsuspected by the clinician. It makes sense, as Drossman et al point out; to pay attention to all the relevant facts when treating patients. ${ }^{16}$

The real value of Beck Depression Inventory screening, which was rapid, simple and well accepted by $98 \%$ of patients, may lie in areas of medicine where psychiatric causes of somatic symptoms are not often appreciated. Early diagnosis of psychiatric disorder, either by screening or by awareness of the prevalence of the disorder, may lead to a shorter period of illness. ${ }^{19} \mathrm{~A}$ wider appreciation that depression is associated with abdominal pain and bowel dysfunction may also save the patient from a number of unnecessary investigations and surgery, so commonly encountered in patients with chronic abdominal pain. ${ }^{20}$

\section{References}

1 White BV, Jones CM. Mucous colitis: a delineation of the syndrome with certain observations on its mechanism and the role of emotional tension as a precipitating factor. Ann Intern Med 1940; 14: 854-72.

2 Bockus HL, Bank J, Wilkinson SA. Neurogenic mucous colitis. Am J Med Sci 1928; 176: 813-29.

3 Young SJ, Alpers DH, Norland CC, Woodruff RA. Psychiatric illness and the irritable bowel syndrome: practical implications for the primary physician. Gastroenterology 1976; 70: 162-6.

4 Hislop IG. Psychological significance of the irritable colon syndrome. Gut 1971; 12: 452-7.

5 Dorfman W. Somatic components of depression. Psychosomatics 1967; 8:4-5.

6 Hill OW, Blendis L. Physical and psychological evaluation of 'non-organic' abdominal pain. Gut 1967; 8: 211-9.

7 Gomez J, Dally P. Psychologically mediated abdominal pain in surgical and medical outpatients. $\mathrm{Br}$ Med J 1977; i: 1451-3.

8 Switz DM. What the gastroenterologist does all day. Gastroenterology 1976; 70: 1048-50.

9 Harvey RF, Salih SY, Read AE. Organic and functional disorders in 2000 gastroenterology outpatients. Lancet 1983; i: 632-4.

10 Ferguson A, Sircus W, Eastwood MA. Frequency of 'functional' gastrointestinal disorders. Lancet 1977; ii: 613-4.

11 Macdonald AJ, Bouchier IAD. Non-organic gastrointestinal illness: a medical and psychiatric study. $\mathrm{Br} J$ Psychiatry 1980; 136: 276-83.

12 Nielsen AC, Williams TA. Depression in ambulatory medical patients. Arch Gen Psychiatry 1980; 37: 999-1004.

13 Beck AT, Ward CH, Mendelson M. An inventory for measuring depression. Arch Gen Psychiatry 1961; 4: 561-71.

14 Rawnsley K. The early diagnosis of depression. Early diagnosis: paper 4. London: Office of Health Economics: 1968.

15 Beck AT, Beck RW. Screening depressed patients in family practice: a rapid technic. Postgrad Med 1972; 52: 81-5.

16 Drossman DA, Sandler RS, McKee DC, Lovitz A. Bowel patterns among subjects not seeking health care. Use of a questionnaire to identify a population with bowel dysfunction. Gastroenterology 1982; 83: 529-34. 17 Thompson WG, Heaton KW. Functional bowel dis- 
orders in apparently healthy people. Gastroenterology 1980; 79: 283-8.

18 Chaudhary NA, Truelove SC. The irritable colon syndrome. $Q$ J Med 1962; 31: 307-22.
19 Johnstone A, Goldberg D. Psychiatric screening in general practice. Lancet 1976; i: 605-8.

20 Kingham JGC, Dawson AM. Origin of chronic right upper quadrant pain. Gut 1985; 26: 783-8.

\section{Forthcoming Scientific Meetings of the British Society of Gastroenterology}

SPRING 1987 - No meeting

AUTUMN 1987 - 15-18 September Jubilee Meeting at the Institute of Education, London

SPRING 1988 - 23-25 March University of Leicester

\section{AUTUMN 1988 - 13-16 September University of Sheffield}

For details of registration please contact: The Administrative Secretary, BSG, 3 St Andrew's Place, Regent's Park, London NW1 4LB.

Tel: 01-387-3534 (International 44-1-387-3534) 